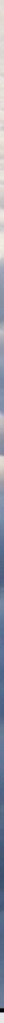

\title{
Influencia de la tormenta tropical Gastón en ola de calor en España (Sep 2016)
}

DOI: $10.31978 / 014-18-009-X .48$

\begin{abstract}
Antonio García MÉndeZ
Ex Área de Técnicas y Aplicaciones de Predicción (ATAP), Agencia Estatal de Meteorología (AEMET)

Ex Meteorological Analyst, European Centre for Medium-range Weather Forecasts -Centro Europeo de Predicción a Plazo Medio- (ECMWF)
\end{abstract}

Este día de invierno hace calor al sol. Pero frío.

UeJima Onitsura, Poeta Japonés

El 22 de agosto de 2016, la tormenta tropical Gastón se desarrolló al suroeste de cabo Verde. Su desplazamiento fue en dirección noroeste hasta el 30 de agosto cuando, al alcanzar los $30^{\circ} \mathrm{N} 55^{\circ} \mathrm{W}$, giró en dirección noreste. El cambio de trayectoria ocasionó una inyección masiva de energía en la circulación de los denominados Oestes (vientos del oeste) en el Atlántico, lo que se tradujo en un aumento notable de la incertidumbre atmosférica. Bajo esta influencia, el flujo zonal en el Atlántico se amplificó rápidamente, desarrollando una configuración omega muy marcada con la dorsal central sobre el suroeste de Europa y norte de África. Una consecuencia fue la llegada a la península ibérica de flujos muy cálidos y secos desde el norte de África.

Palabras clave: sistemas de predicción por conjuntos aplicados a la predicción de corto y medio plazo, predicción probabilista, tormenta tropical Gastón, ola de calor en España septiembre 2016. 


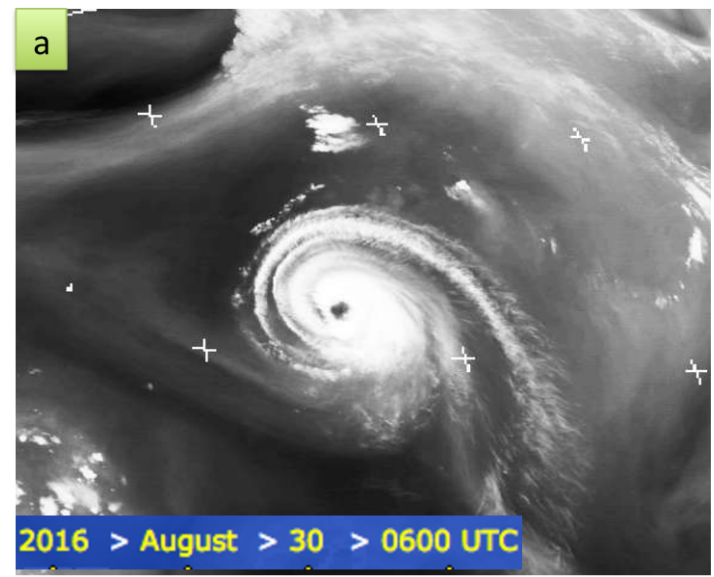

Date 2016083100 UTC @ECMWF

Probability that GASTON will pass within $120 \mathrm{~km}$ radius during the next 240 hours

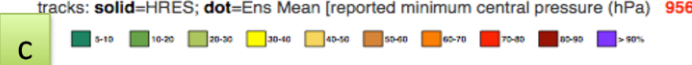

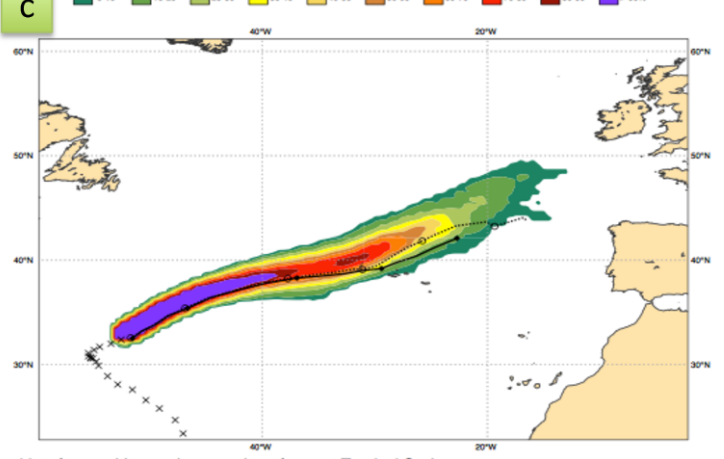

b

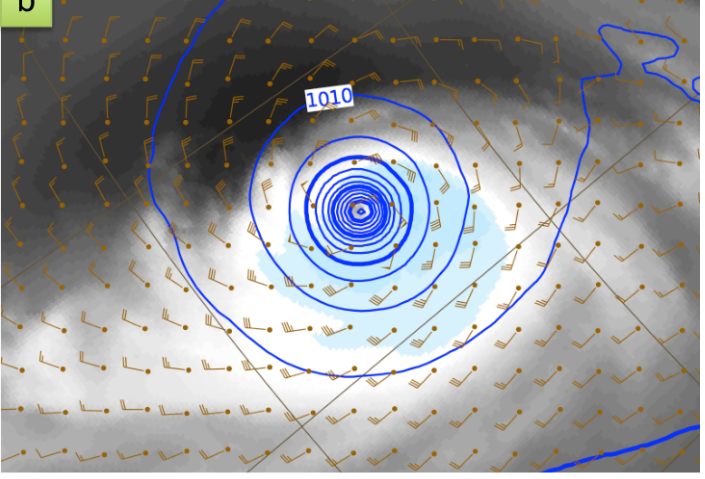

Wednesday 31 Aug 2016, 00 UTC Step 72 OBSERVATION TRACKING FOR GASTON (07L) CYCLONE LIFETIME : 20160823 TO 20160903

d

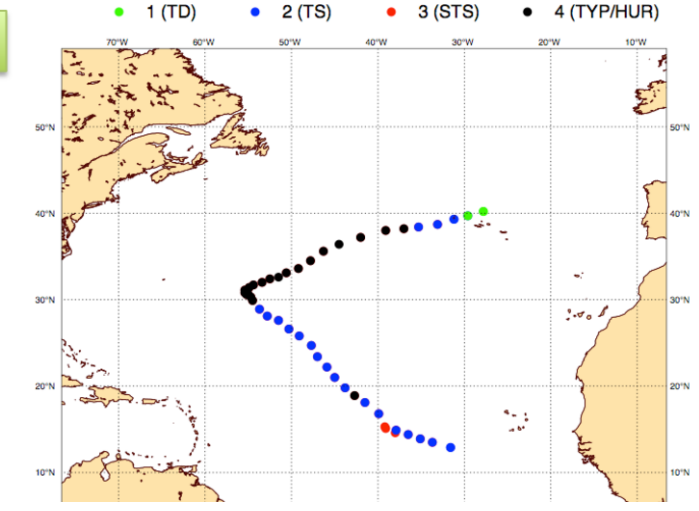

Figura 48.1: (a) Imagen WV con el huracán Gastón el 30 de agosto de 2016

(b) Imagen simulada WV ECMWF y MSLP H+72 VT: 31 de agosto de 2016; 00 UTC (c) Probabilidad de Gastón de pasar en un radio de $120 \mathrm{~km}$. ECMWF H+O0 a H+240 (d) Posicion observada de Gastón 23 de agosto de 2016 a 3 de septiembre de 2016.

\subsection{Descripción sinóptica y pre- dicción mensual}

La Figura 48.1 muestra al huracán Gastón el 30 de agosto de 2016, una simulación determinista a 72 horas, el seguimiento probabilista de su trayectoria a partir del 31 de agosto y finalmente la trayectoria observada desde el 23 de agosto al 3 de septiembre de 2016. Los puntos que marcan la trayectoria están coloreados de acuerdo a la categoría de la perturbación. TD (depresión tropical), TS (tormenta tropical), STS (tormenta tropical severa) y TYP/HUR (huracán).

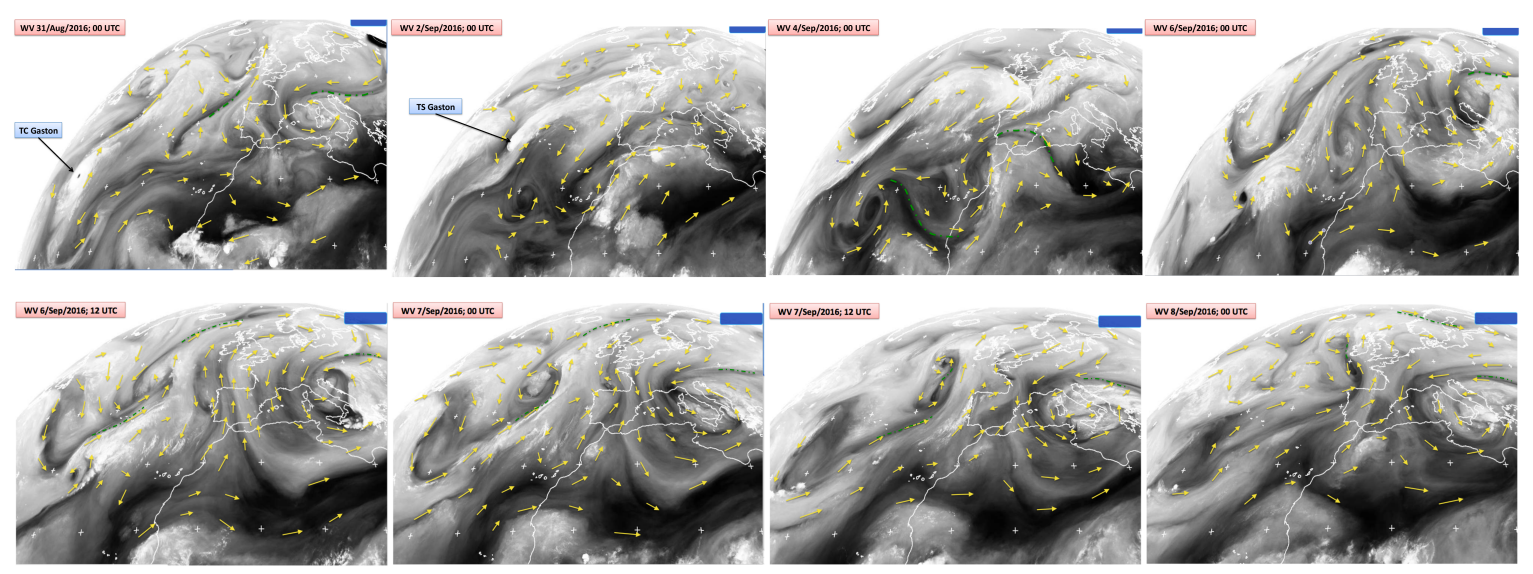

Figura 48.2: Imágenes Meteosat WV, flujo superpuesto subjetivamente, para 31 de agosto 00 UTC y 2 a 7 de septiembre de 2016. 


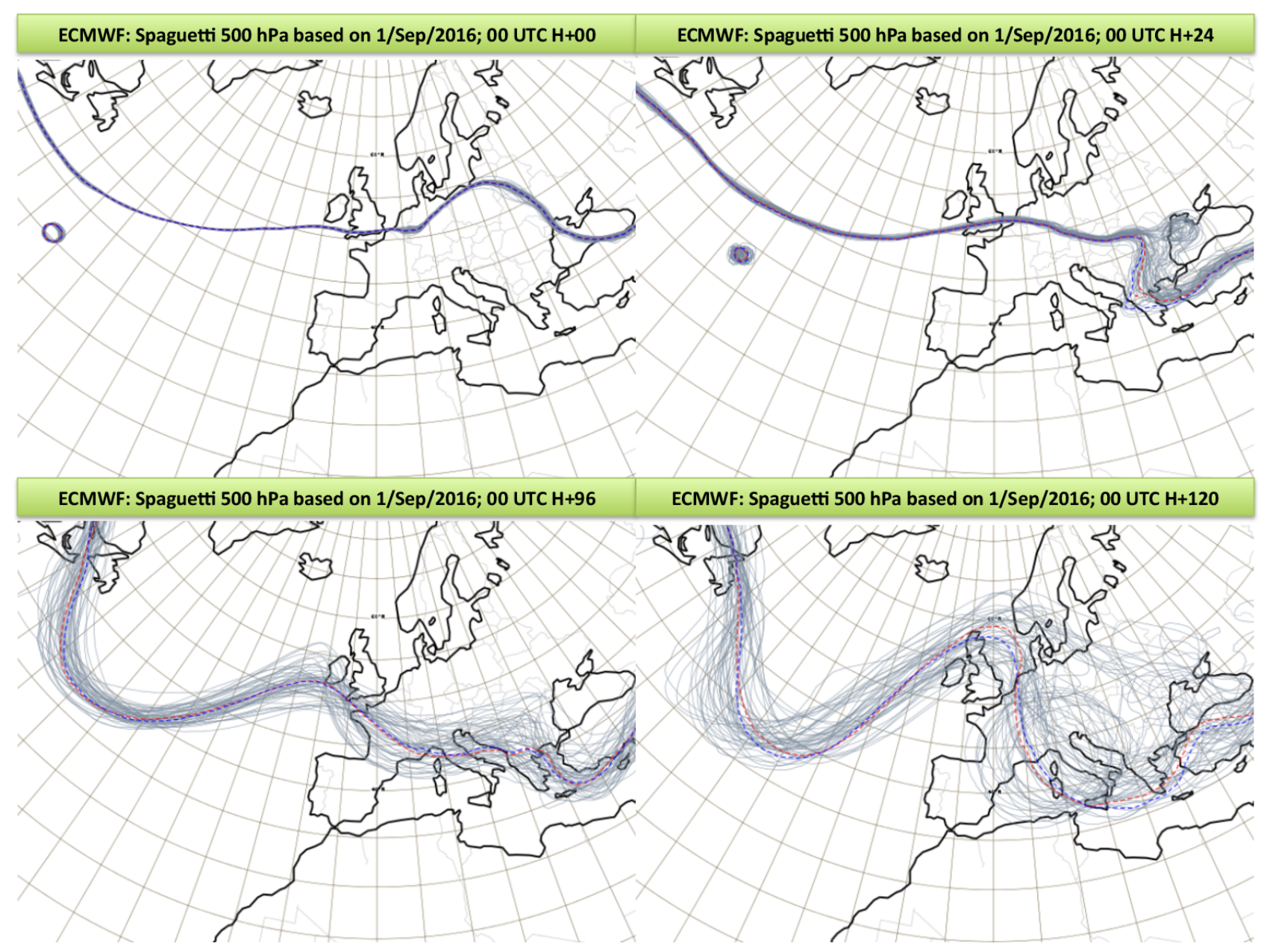

Figura 48.3: Espaguetis (ver 27.2.2 en la página 404) del campo de altura geopotencial en 500 hPa, para 560 dam basados en el 1 de septiembre de 2016 a 00 UTC (H+O0, H+24, H+96 y H+120).

La Figura 48.3, muestra como el ECENS describe la captura de los restos de Gastón y el impacto brutal que esta captura tiene, perturbando extraordinariamente un flujo zonal y desarrollando una configuración omega con gran amplitud.

Esta descripción prevista por el ECENS, queda corroborada por lo que se aprecia en las imágenes de WV de la Figura 48.2 en la página anterior. El desarrollo muy rápido de la dorsal sobre las islas británicas entre el 2 y el 4 de septiembre, atrae flujos africanos de componente sur sobre la península ibérica. Este flujo cálido y muy seco queda aún más realzado por la presencia de una baja en los alrededores del golfo de Cádiz.

La predicción mensual [1] comienza a dar señales de anomalías cálidas (respecto al clima del modelo) con tres semanas de anticipación, dos semanas antes la señal es muy clara no solo sobre la península ibérica, sino también extendiéndose a Europa occidental y central. La excepción a estas anomalías cálidas se cirscunscribe al oeste de Portugal. Ver Figuras 48.4, 48.5 y 48.6 en la página siguiente.

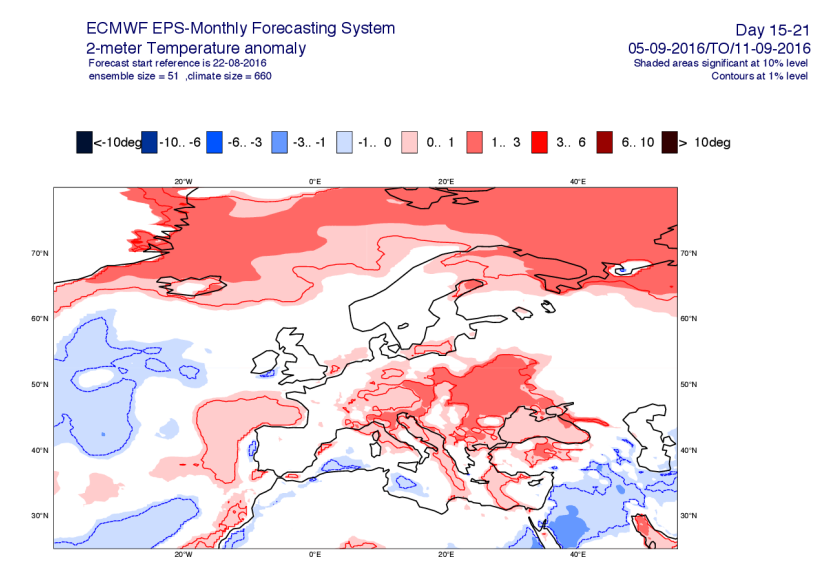

Figura 48.4: ECMWF Predicción mensual, semana+3, VT: 5-11 de septiembre de 2016. 


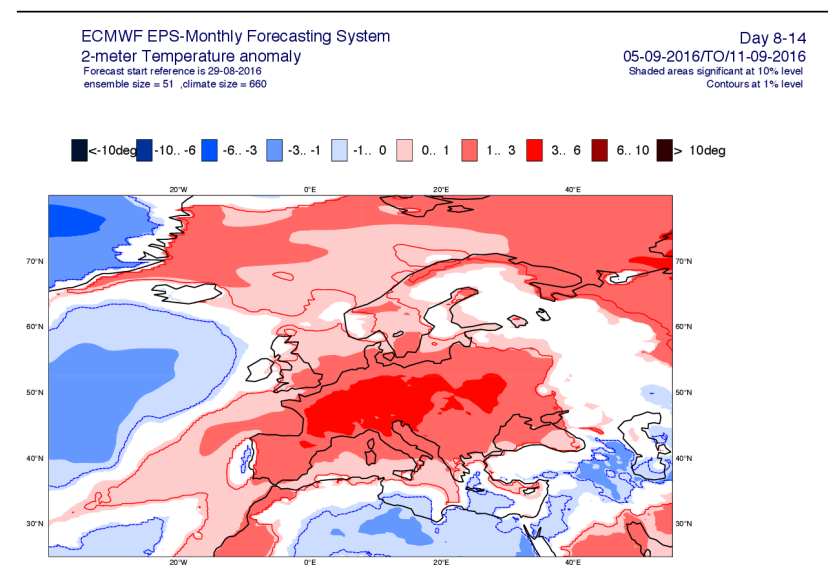

Figura 48.5: ECMWF Predicción mensual, semana +2 , VT: 5-11 de septiembre de 2016.

ECMWF EPS-Monthly Forecasting System 2-meter Temperature anomaly
Forecas start relerence is $0109-092016$

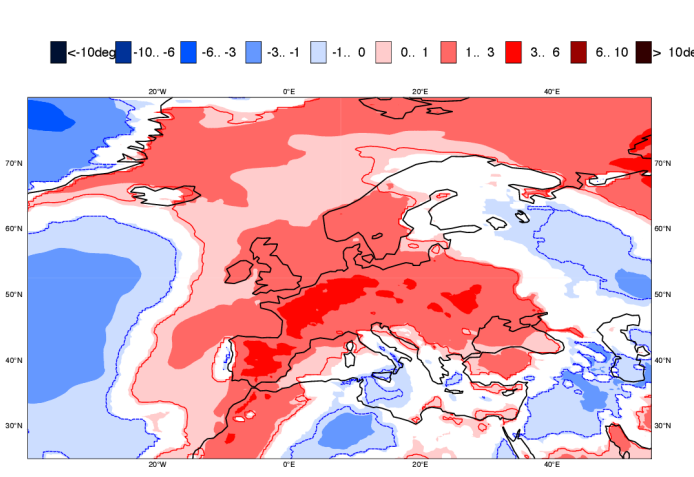

Figura 48.6: ECMWF Predicción mensual, semana +1 , VT: 5-11 de septiembre de 2016.

Cuando hablamos de anomalías, obviamente necesitamos un patrón de comparación. Este patrón esta constituido por el clima del modelo (ver detalles en 27.7.1 en la página 419). Este clima se calcula en la actualidad dos veces a la semana, usando siempre la versión operativa del IFS. El cálculo consiste en repredicciones usando 10 miembros ECENS más el miembro de control, 5 semanas (la semana en curso, las dos anteriores y las dos posteriores) para los últimos 20 años. El resultado final se construye usando 9 conjuntos de repredicciones siendo la fecha central la del Jueves o Lunes anterior mas próximo a la ensemble a utilizar. En resumen, tenemos 20 años x 11 miembros x 9 repredicciones $=1980$ valores que describen el clima del modelo para un lugar dado y un rango de predicción. Este clima se utiliza no solo para la predicción mensual, sino también para los parámetros derivados del ECENS, como son el EFI y el SOT de los que vamos a ver detalles más adelante.

\subsection{ECENS}

En las Figuras 48.7 y 48.8 en la página siguiente, se muestran series temporales de predicción de temperaturas a 2 metros, máxima y mínima, para Sevilla y Córdoba con base en la pasada del 3 de septiembre de 2016 a 00 UTC. El tamaño de las cajas en estos gráficos está directamente relacionado con la dispersión del ECENS para cada parámetro y rango de predicción. Igualmente, las marcas que aparecen en las cajas, tienen relación con el porcentaje de miembros del ECENS que predicen un determinado valor. Una explicación cualitativa aparece, superpuesta, en la parte superior de cada figura.

Tanto en las series de Sevilla como en la de Córdoba, se aprecian valores de la temperatura máxima prevista sobre el percentil 90 del clima durante cinco días consecutivos, desde el 3 hasta el 7 de septiembre; y superando el percentil 99 los días 5 y 6 .

Sevilla, Spain $37.32^{\circ} \mathrm{N} 5.94^{\circ} \mathrm{W}$ (ENS land point) $2 \mathrm{~m}$

Extended Range Forecast based on ENS distribution Saturday 3 September 201600 UT

5 days in a row with tmax exceeding model climate $90 \%, 5^{\text {th }}$ and $6^{\text {th }}$ Sept on the 99 percentile

$2 \mathrm{~m} \mathrm{~min} / \mathrm{max}$ Temperature ( $\mathrm{C}$ ) reduced to $2 \mathrm{~m}$ (station height) from $31 \mathrm{~m}$ (ENS)

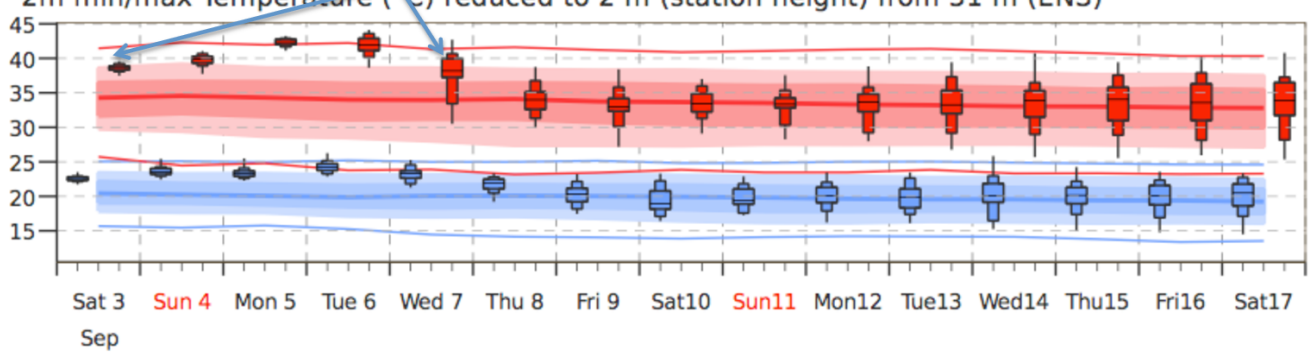

Figura 48.7: EPSgramas 15 días, temperatura a dos metros (T2m) con clima para Sevilla. 


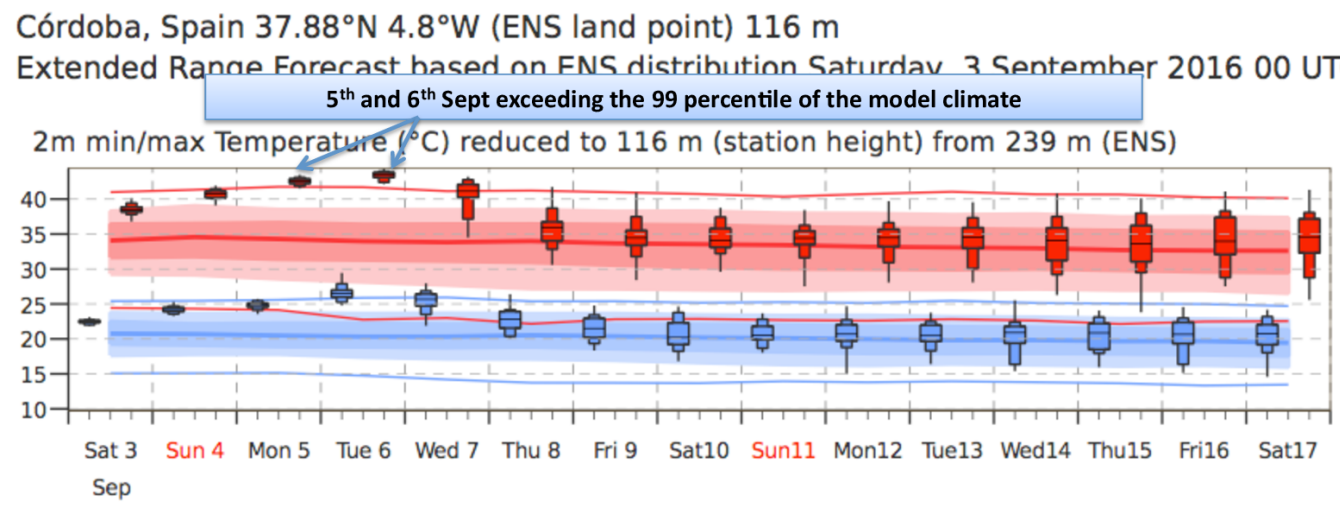

Figura 48.8: EPSgramas 15 días, T2m con clima para Córdoba.

Esta pauta, traducida en números redondos significa que solo en 20 ocasiones los valores del clima han superado este umbral durante los últimos 20 años. Por lo que, en promedio, cada verano el percentil 99 solo se supera en una ocasión y en el caso que nos atañe la predicción del ECENS nos dice que se va a superar dos días consecutivos, lo que supone una situación de extrema rareza.

Los EPSgramas de Cáceres y Madrid de las Figuras 48.9 y 48.10, muestran de nuevo cinco días conse- cutivos con temperaturas máximas superando el percentil 90 y alcanzando o superando el percentil 99 dos de estos días. El máximo de temperaturas alcanza Madrid un día mas tarde que en Andalucía y Extremadura.

Estos EPSgramas muestran claramente un caso extremo. El clima del modelo para temperaturas máximas en el percentil 99 se puede ver en la Figura 48.11 en la página siguiente. Aquí pueden apreciarse valores que superan $\operatorname{los} 40^{\circ} \mathrm{C}$ en el valle del Guadalquivir.

Cáceres, Spain $39.43^{\circ} \mathrm{N} 6.43^{\circ} \mathrm{W}$ (ENS land point) $403 \mathrm{~m}$

Extended Range Forecast based on ENS distribution Saturday 3 September 201600 UT

$2 \mathrm{~m} \mathrm{~min} / \mathrm{max}$ Temperature $\left({ }^{\circ} \mathrm{C}\right)$ reduced to $403 \mathrm{~m}$ (station height) from $401 \mathrm{~m}$ (ENS)

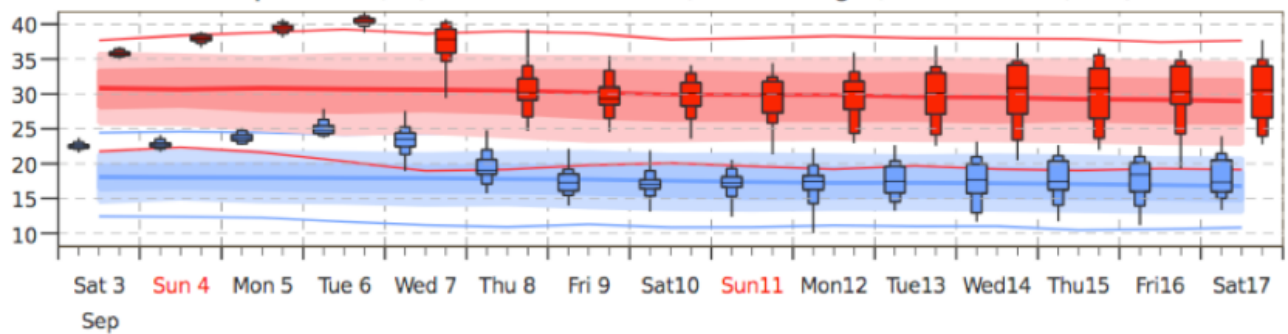

Figura 48.9: EPSgramas 15 días, T2m con clima para Cáceres y Madrid.

Madrid, Spain $40.41^{\circ} \mathrm{N} 3.78^{\circ} \mathrm{W}$ (ENS land point) $638 \mathrm{~m}$

Extended Ranae Forecast based on FNS distribution Saturdav 3 Sentember 201600 UT 4 days in a row with tmax on or above the upper percentile of the model climate

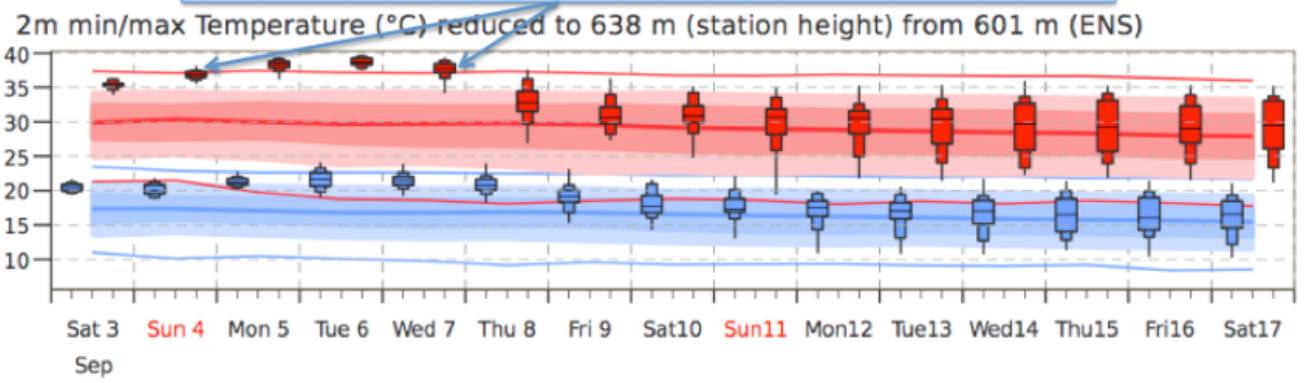

Figura 48.10: EPSgramas 15 días, T2m con clima para Cáceres y Madrid. 


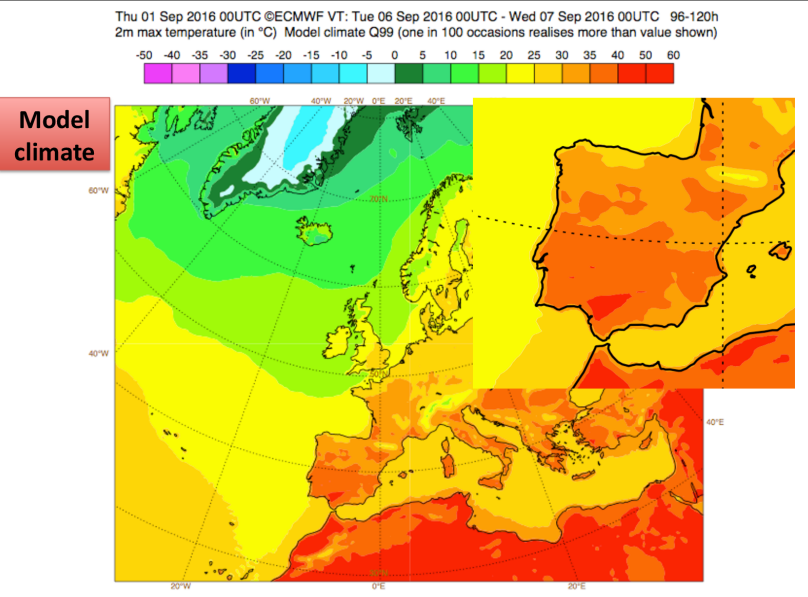

Figura 48.11: Clima del modelo tmax percentil 99, 0609-2016.

El índice de predicciones extremas EFI (Extreme Forecast Index, ver sección 27.7.2 en la página 420), es un parámetro que evaluá en que medida las predicciones del ECENS se apartan de los valores climáticos. Este índice esta normalizado con un rango entre -1 $y+1$. Un valor $E F I=-1$ significa que todas las predic- ciones están por debajo del valor mínimo del clima y un valor $\mathrm{EFI}=+1$ significa que todas superan el valor máximo del clima.

La Figuras 48.12 y 48.13 , muestra predicciones EFI validas para el 7 de septiembre usando distintos rangos de predicción. Se observa un incremento gradual de este índice según nos aproximamos a la fecha antes citada. Superpuesto al EFI, en estos gráficos se muestra también el llamado SOT (Shift of Tails, ver sección 27.7.3 en la página 421) que podría traducirse como desplazamiento en los extremos. Este índice nos proporciona información sobre como es de extremo un fenómeno previsto. La señal del SOT surge cuando un número apreciable de predicciones ECENS superan el valor máximo o están por debajo del valor mínimo. La utilidad del SOT estriba en que, en tales casos extremos, el EFI pierde información en las colas de la distribución ECENS. Algunos detalles sobre su cálculo se muestran en las Figuras 48.17 en la página 748 y 48.18 en la página 748 (más detalle en la sec. 27.7.2 en la página 420 y la sec. 27.7 .3 en la página 421).

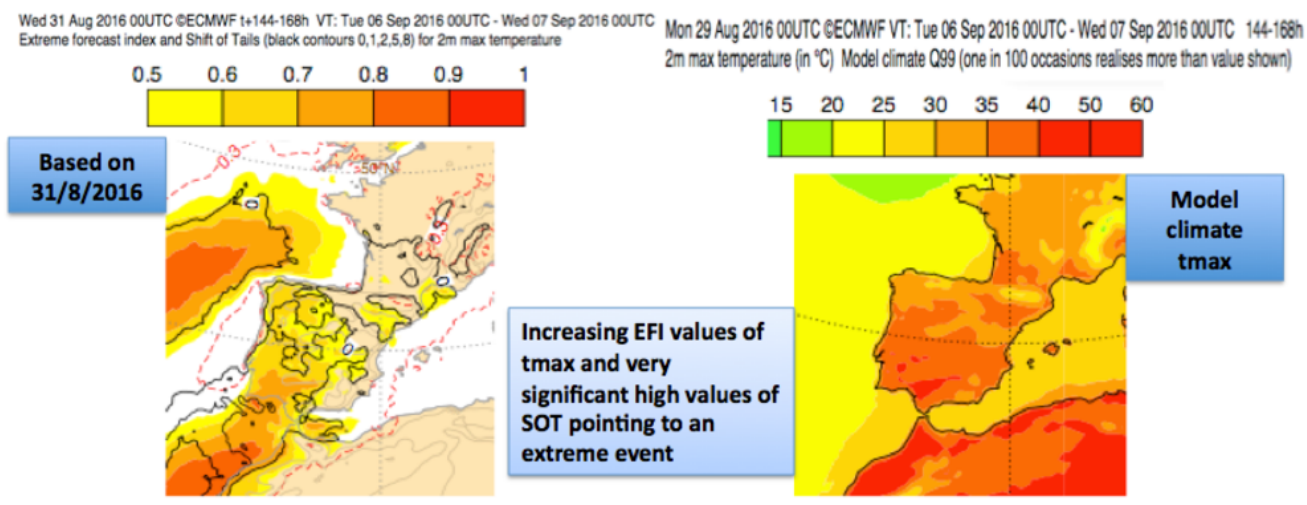

Figura 48.12: ECENS 31-08-2016 H+144-168 VT: 06-09-2016 00 UTC - 07-09-2016 00 UTC. Izquierda: EFI y SOT T2m. Derecha: percentil 99 de la climatología correspondiente.

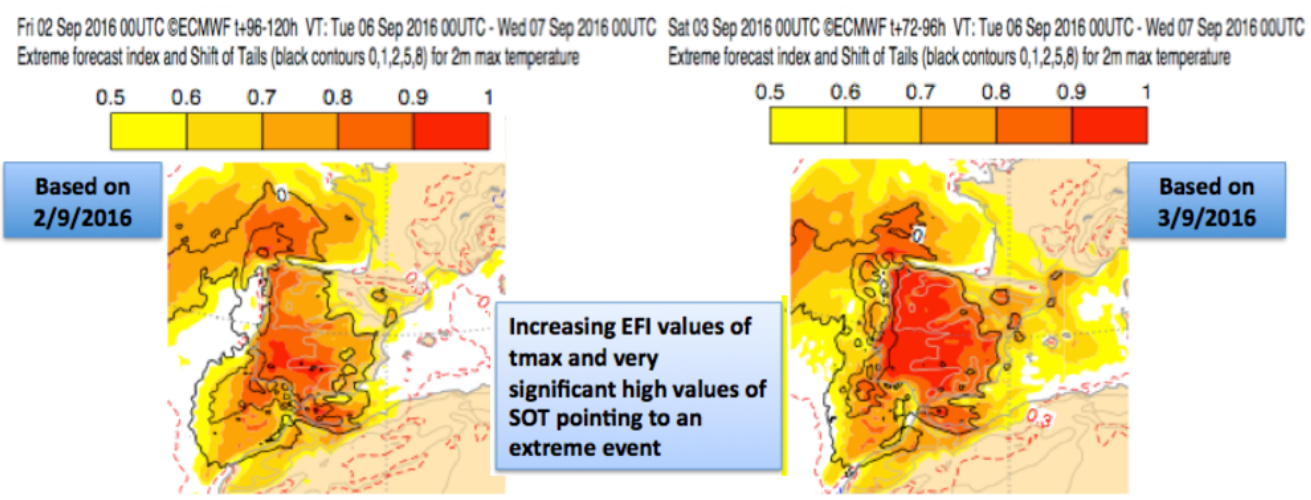

Figura 48.13: ECENS 02-09-2016 H+96-120 VT: 06-09-2016 00 UTC - 07-09-2016 00 UTC, EFI y SOT T2m. Derecha: los mismo para ECENS 02-09-2016 H+72-96. 


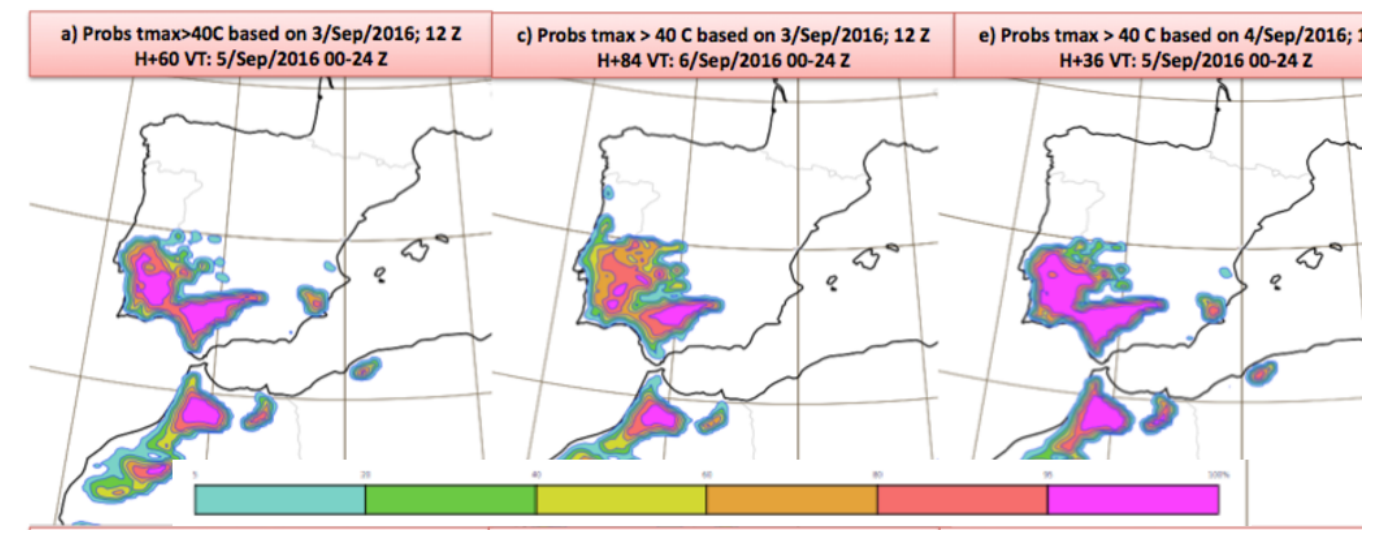

Figura 48.14: Probabilidades de $T_{\max }>40^{\circ} \mathrm{C}$.

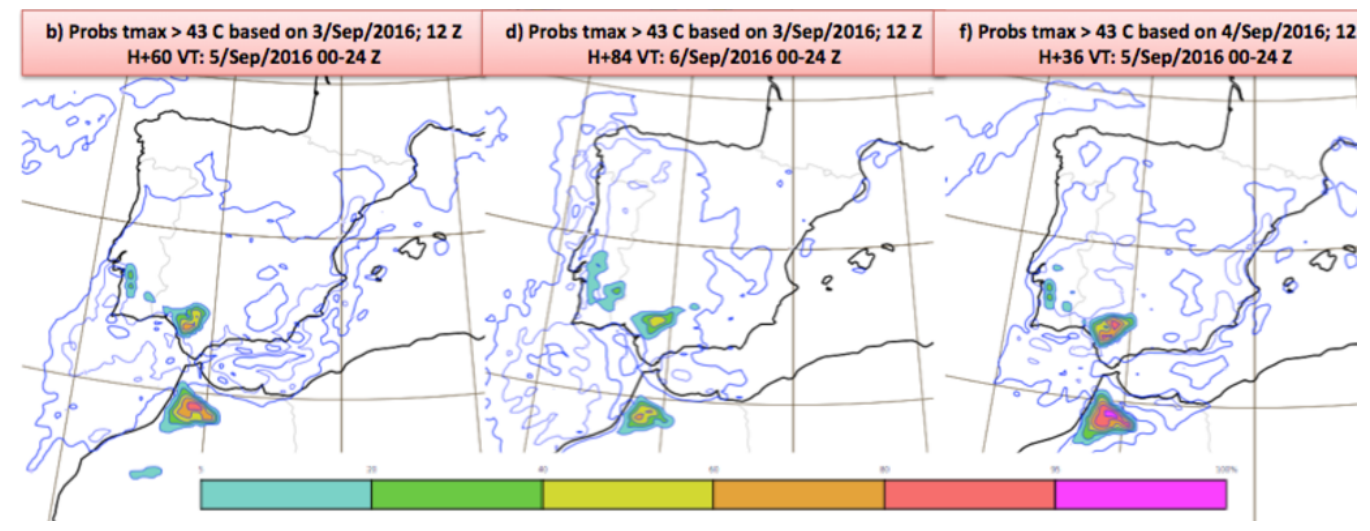

Figura 48.15: Probabilidades de $T_{\max }>43^{\circ} \mathrm{C}$.

Otra importante aportación del ECENS es la posibilidad de producir datos y gráficos de probabilidades usando diferentes umbrales y parámetros. Esto es lo que muestra las Figuras 48.14 y 48.15, donde aparecen probabilidades (ver sección 27.6.1 en la página 416) de que la temperatura máxima supere $\operatorname{los} 40^{\circ} \mathrm{C}$ y los $43{ }^{\circ} \mathrm{C}$. El valle del Guadalquivir marca la zona donde los valores máximos absolutos se podrían registrar de acuerdo con el ECENS.

Otra aplicación muy valiosa del ECENS para parámetros, rango de predicción y localidades concretas es la evaluación de las CDF (Cumulative Distribution Functions) o funciones de distribución acumuladas. En ellas se representan el clima del modelo (línea negra) y las predicciones ECENS (en colores) para rangos diferentes de predicción, todas ellas válidas para el mismo periodo temporal. Aquí puede evaluarse no solo cuantitativa sino cualitativamente el EFI. La pendiente de las curvas EFI aportan también una información valiosa, cuanto mayor es la pendiente de estas curvas menor es la dispersión, dispersiones grandes se corresponden con curvas con pendientes menores.

La Figura 48.16 en la página siguiente, muestra un ejemplo de una predicción de temperatura media a 2 metros para Sanlúcar la Mayor, en la provincia de Sevilla, válida el 5 de septiembre. En este gráfico, se observan en primer lugar curvas ECENS con una pendiente alta y por tanto pequeña dispersión (lo que se traduce en un alto grado de confianza). Además puede evaluarse fácilmente, por ejemplo, la probabilidad de que la temperatura media a 2 metros supere $\operatorname{los} 32^{\circ} \mathrm{C}$. En este caso, la probabilidad citada es del $80 \%$ en la predicción ECENS, mientras que es del $0 \%$ en el clima del modelo. Las figuras 48.17 y 48.18 en la página siguiente, muestran algo similar para Cáceres y Córdoba el 6 de septiembre. Aquí, nuevamente, se aprecia un número notable de valores ECENS que superan el máximo del clima. También se muestran en esta figura, detalles sobre el cálculo del SOT para el percentil 90. No hace falta añadir mucho mas, para darnos cuenta que estamos ante un caso realmente extremo con temperaturas muy altas incluidas en el percentil superior del clima. 


\section{CDF for mean $\mathbf{t} 2 \mathrm{~m}$. The location is close to Sanlucar la Mayor (Sevilla)}

Forecast and M-Climate cumulative distribution functions with EFI values
$37.32^{\circ} \mathrm{N} 6.17^{\circ} \mathrm{W}$
Valid for 24 hours from Monday 5 September 201600 UTC to Tuesday 6 September 201600 UTC

Valid for 24 hours from Monday 5 September 201600 UTC to Tuesday 6 Se
The probability of mean $\mathbf{t} \mathbf{2} \mathbf{m}$ to exceed $\mathbf{3 2 C}$ is $\mathbf{8 0 \%}$ in the forecast and $0 \%$ in the model climate
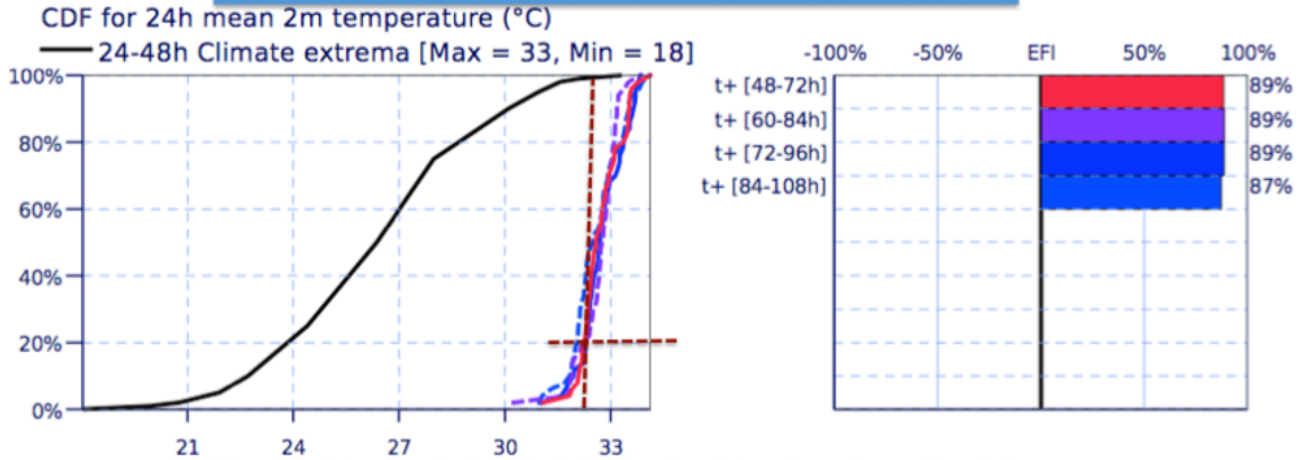

Figura 48.16: T2m media CDF para un lugar cercano a Sanlúcar la Mayor. VT: 05-09-2016.

\section{CDF de la t2m media para una posicion cercana a Cáceres}

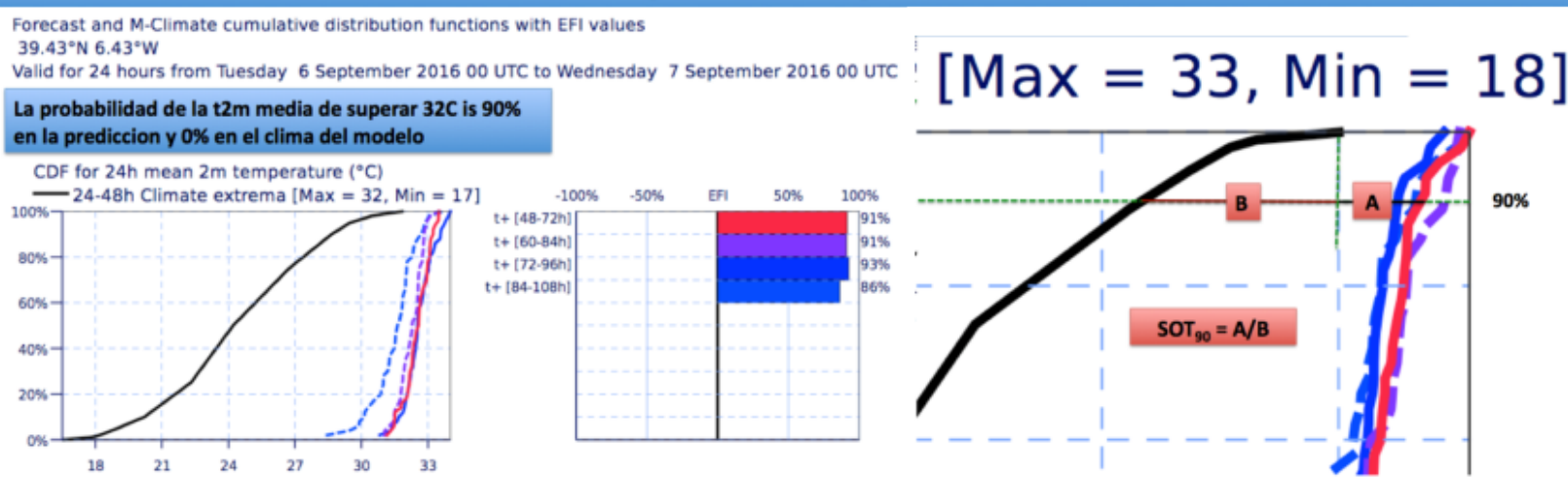

Figura 48.17: T2m media CDF y SOT para un lugar cercano a Cáceres. VT: 06-09-2016.

Forecast and $\mathrm{M}$-Climate cumulative distribution functions with EFI values $37.88^{\circ} \mathrm{N} 4.8^{\circ} \mathrm{W}$

Valid for 24 hours from Tuesday 6 September 201600 UTC to Wednesday 7 September 201600 UTC
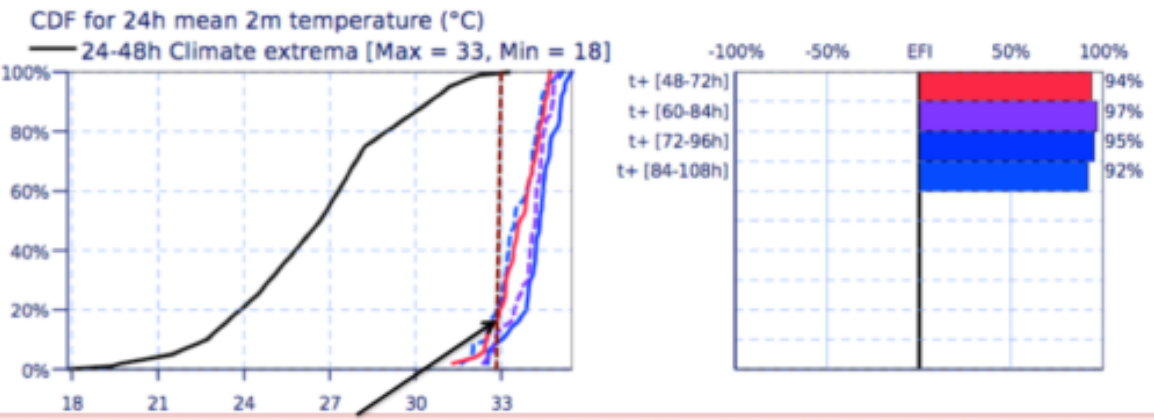

La probabilidad de que la $2 \mathbf{2 m}$ media sea superior a $33 \mathrm{C}$ es $80 \%$ en la prediccion y $0 \%$ en el clima

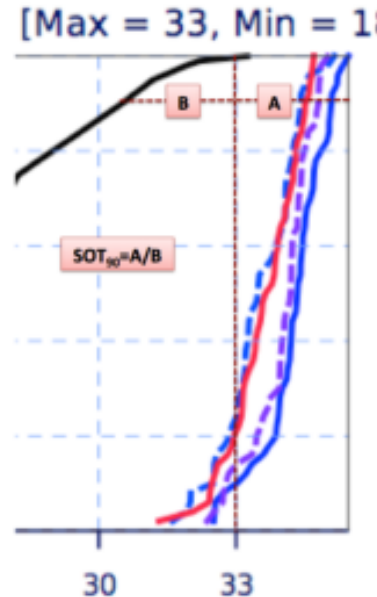

Figura 48.18: T2m media CDF y SOT para un lugar cercano a Córdoba. VT: 06-09-2016. 


\subsection{Modelo determinista}

Las Figuras 48.19, 48.20 y 48.21 muestran predicciones a corto plazo de geopotencial y temperatura a
850 hPa válidas para el 6 y 7 de septiembre. En estas predicciones a corto plazo deterministas se observa claramente la irrupción de aire africano extremadamente cálido.
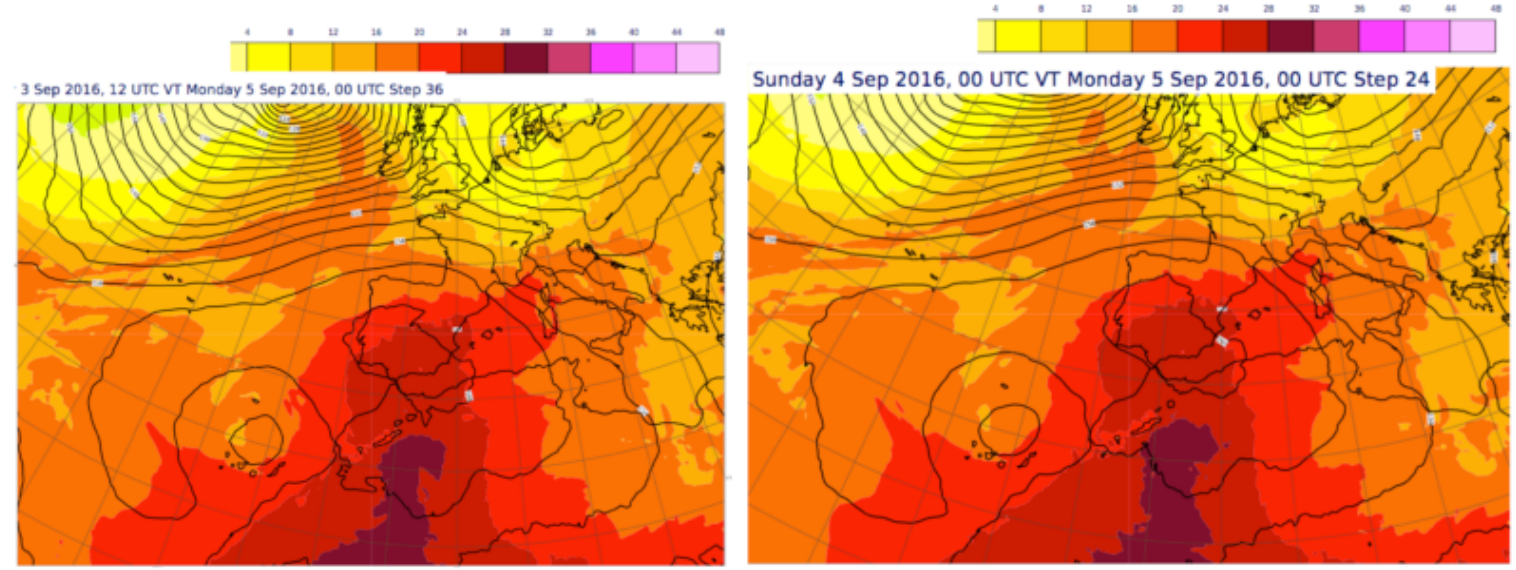

Figura 48.19: Predicción determinista Z850 y T850 hPa H+36 y H+24, VT: 05-09-2016 00 UTC.
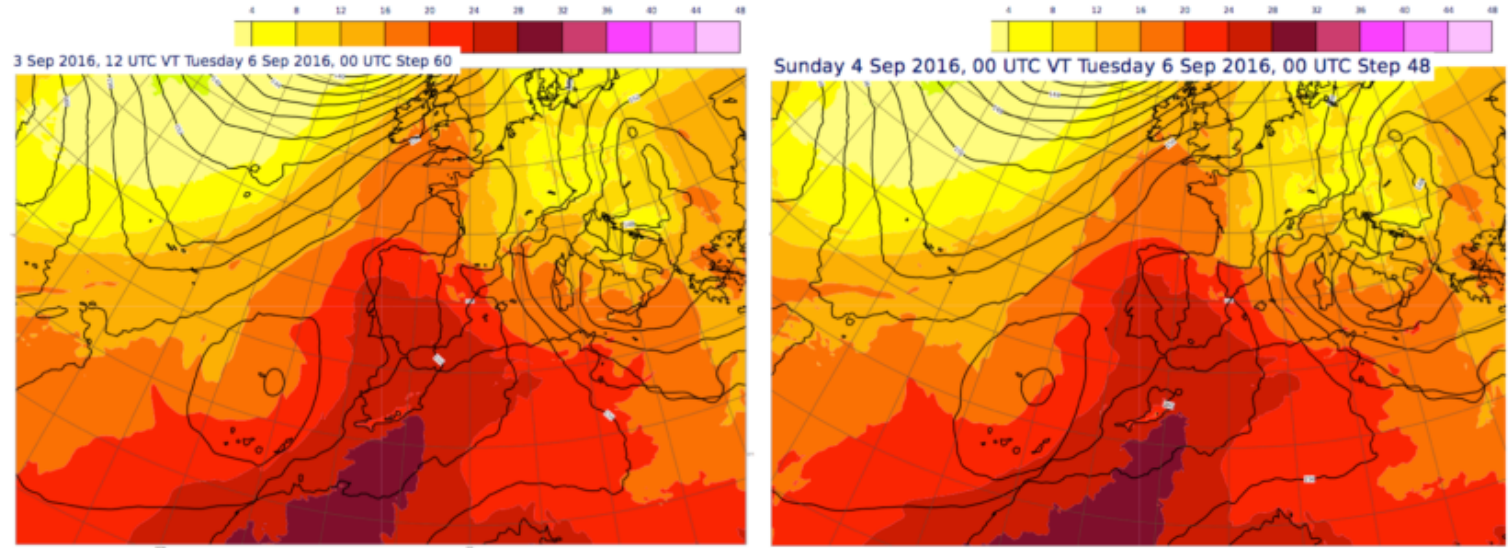

Figura 48.20: Predicción determinista Z850 y T850 hPa, H+60 y H+48 VT: 06-09-2016 00 UTC.
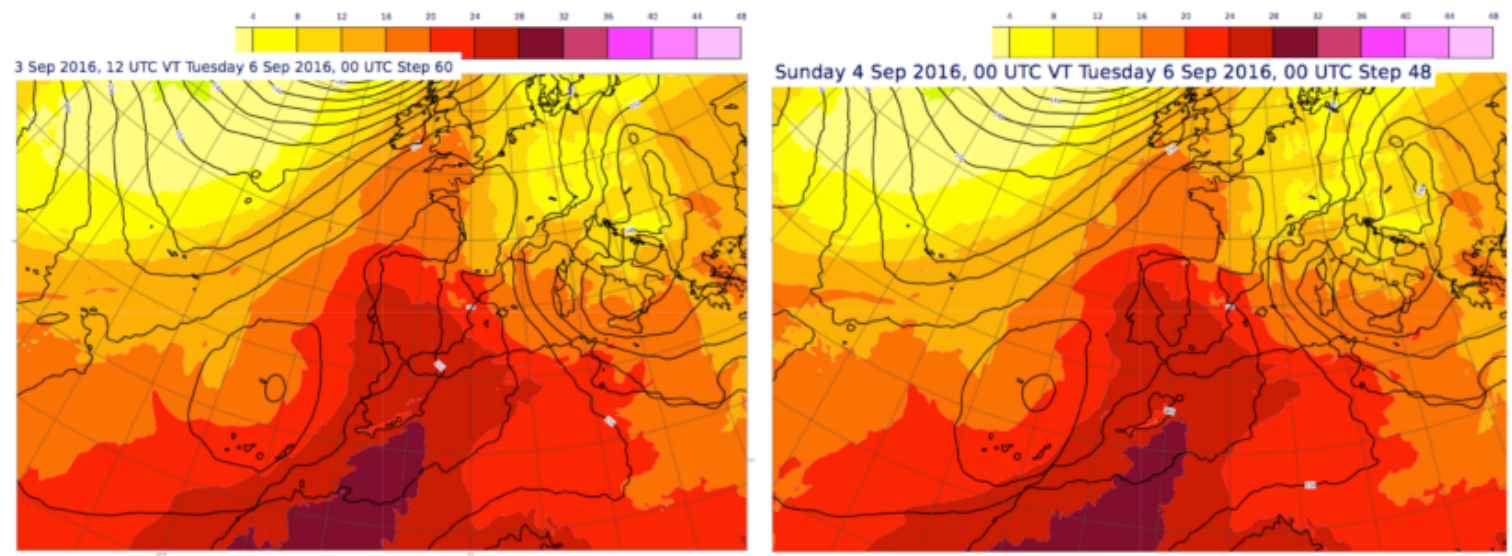

Figura 48.21: Predicción determinista Z850 y T850 hPa, H+24 VT: 06-09-2016 00 UTC y H+48 VT: 07-09-2016 OO UTC. 


\subsection{Observaciones}

Las observaciones sinópticas (ver surface synoptic observations (SYNOP)) que se utilizan para construir las series temporales de las Figuras 48.22 y 48.23 , verificaron lo extraordinario del caso. En estas series, se muestran reportes sinópticos de temperatura y punto de rocío a 2 metros, de las estaciones de Sevilla, Cór- doba, Murcia y Madrid. Los registros observados de 44.3, 44.8 y $43.2^{\circ} \mathrm{C}$ en Sevilla, Córdoba y Murcia, respectivamente, el 5 de septiembre, si bien no rompen el récord absoluto de la época de $47.2^{\circ} \mathrm{C}$ en Murcia (julio 1994) y $46.6^{\circ} \mathrm{C}$ en Sevilla y Córdoba (julio 1995), no anduvieron muy lejos (en la actualidad, la tendencia a batir récords de temperaturas máximas es creciente: se baten todos los años, muchos meses, en muchísimas localidades).
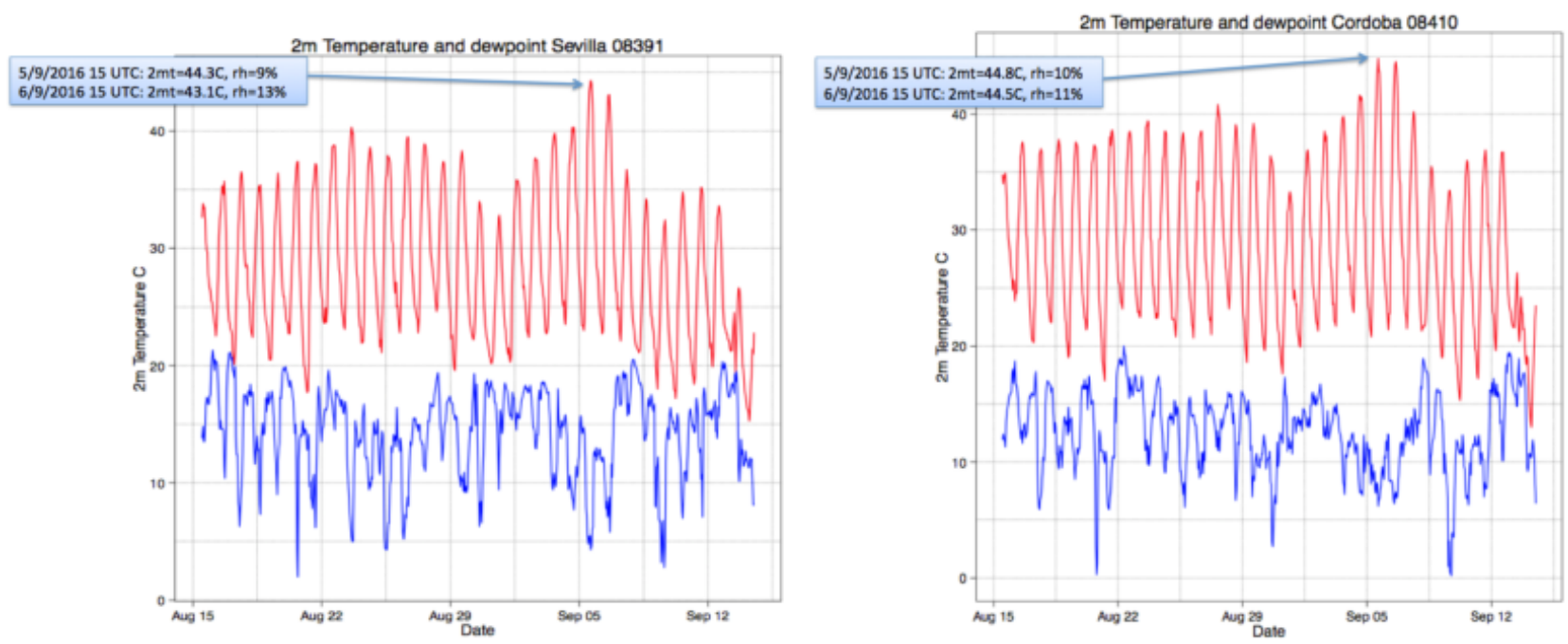

Figura 48.22: Series de temperatura y punto de rocío a $2 \mathrm{~m} .15$ de agosto a 15 de septiembre de 2016. Datos extraídos de report sinópticos: Sevilla y Córdoba.
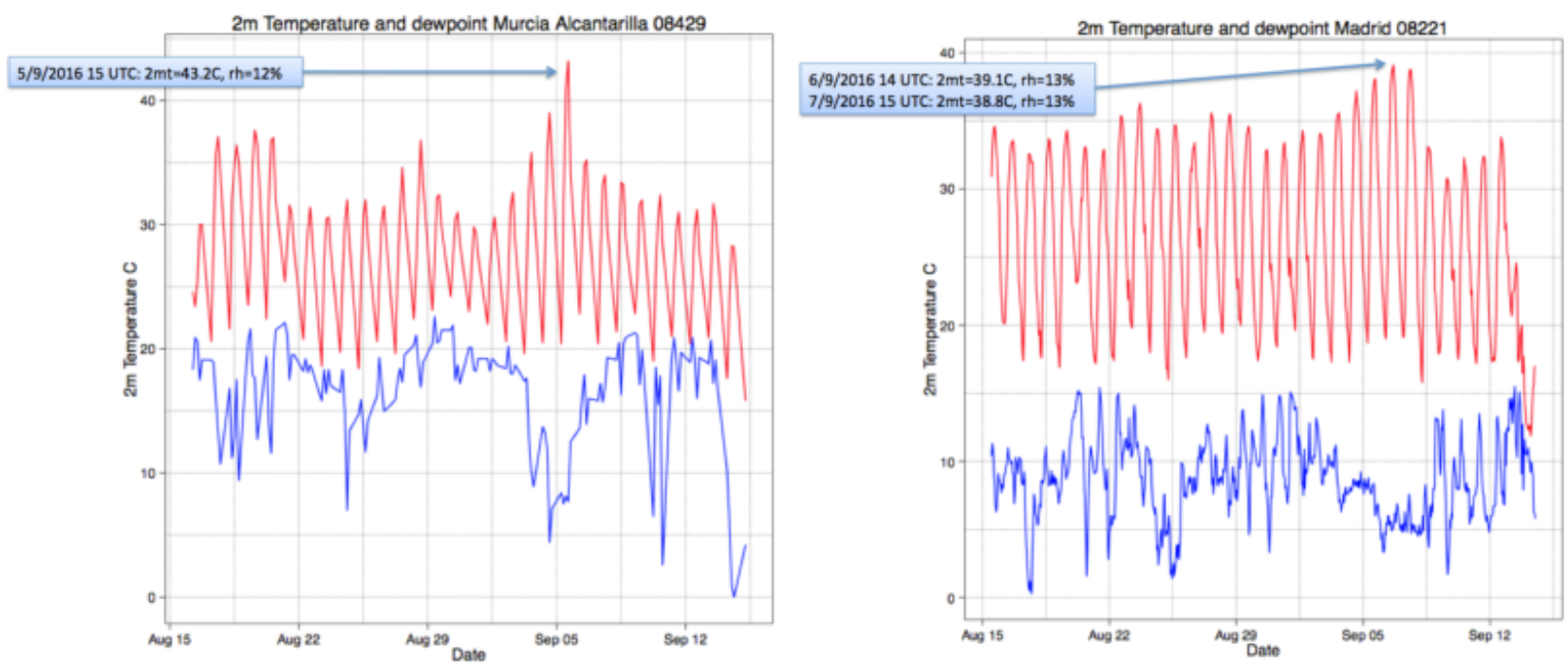

Figura 48.23: Como Figura 48.22, Murcia y Madrid. 
Los perfiles de los sondeos (ver sondeo meteorológico) de Madrid (6 de septiembre a 12 UTC y 8 de septiembre a 12 UTC) y La Coruña (7 y 8 de septiembre a 00 UTC) se muestran en las Figuras 48.24 y 48.25 , respectivamente. La ausencia de humedad es evidente en estos perfiles. Finalmente, la entrada de un frente frío la noche del 7 de septiembre por Galicia desplazó el aire caliente de la península ibérica.
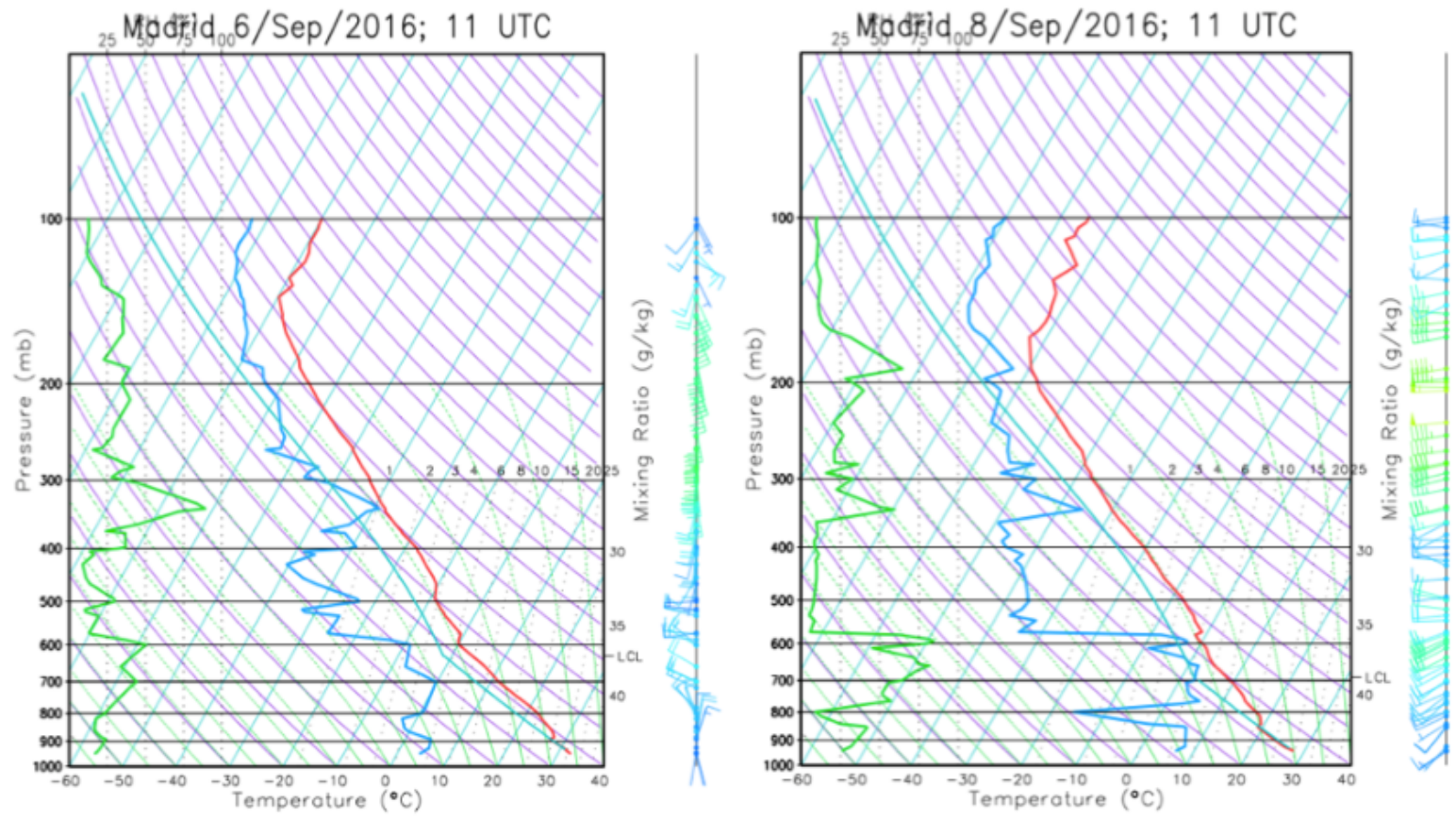

Figura 48.24: Sondeos de Madrid 06-09-2016 a 12 UTC y 08-09-2016 12 UTC.
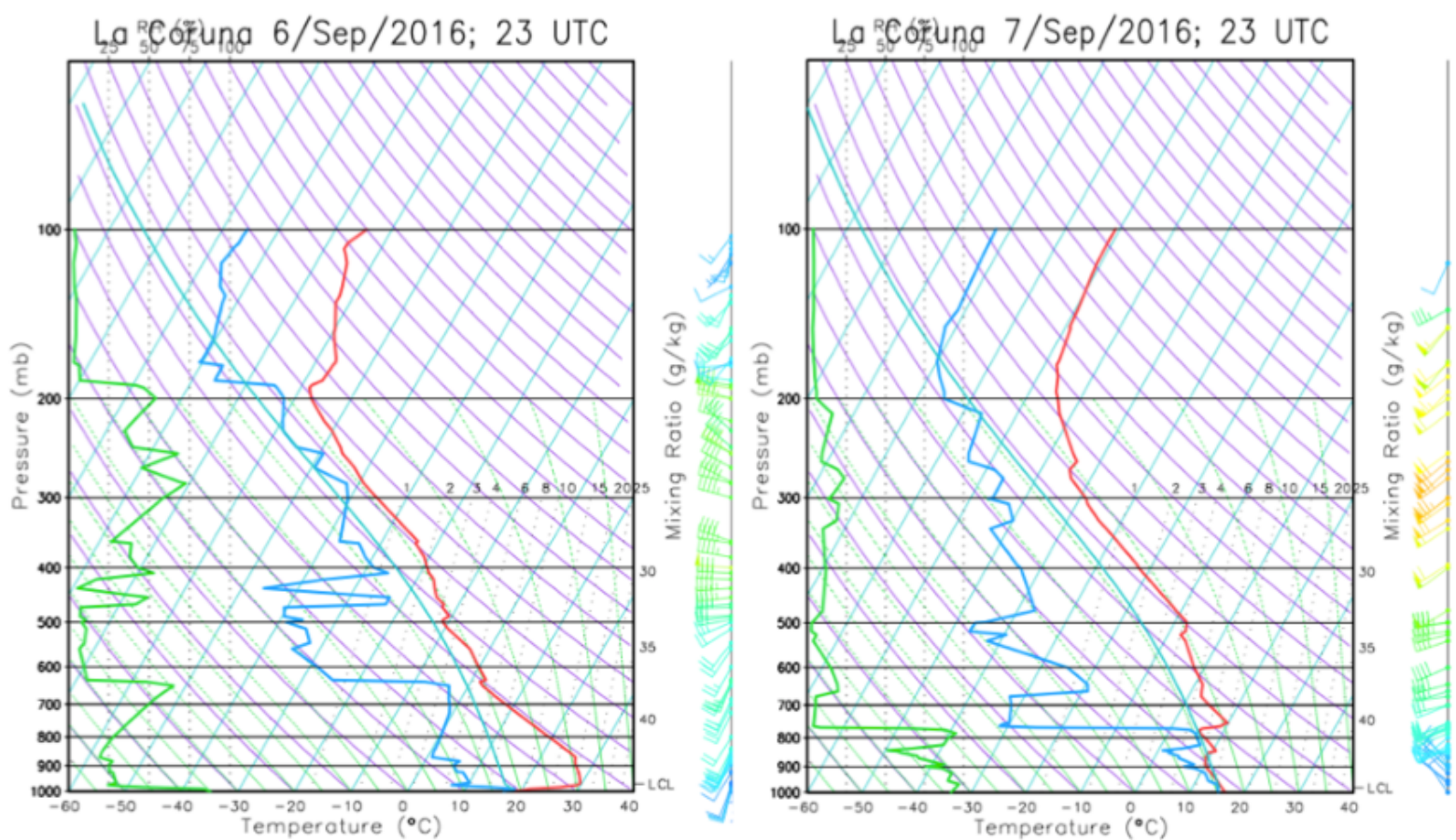

Figura 48.25: Sondeos de La Coruña 07-09-2016 a 00 UTC y 08-09-2016 a 00 UTC. 


\begin{tabular}{|c|c|c|c|c|c|c|c|c|c|c|c|c|c|c|}
\hline & & & \multicolumn{2}{|c|}{ MADRID } & \multicolumn{2}{|c|}{ LA CORUÑA } & \multicolumn{2}{|c|}{ SANTANDER } & \multicolumn{2}{|c|}{ MURCIA } & \multicolumn{2}{|c|}{ BARNA } & \multicolumn{2}{|c|}{ PALMA } \\
\hline & & & TT (C) & $\mathrm{RH}(8)$ & TT (C) & RH $(8)$ & TT (C) & RH (8) & TT (C) & $\mathrm{RH}(8)$ & TT (C) & RH ( 8$)$ & TT (C) & $\mathrm{RH}(8)$ \\
\hline Date: & $04 / 09 / 2016$ & 23:00 & 24.5 & 30.4 & 16.4 & 27.0 & 17.1 & 45.1 & 25.8 & 18.0 & 23.1 & 36.9 & 23.4 & 29.3 \\
\hline Date: & $05 / 09 / 2016$ & $11: 00$ & 23.3 & 33.0 & 19.4 & 12.7 & 16.2 & 33.1 & 26.0 & 19.0 & 20.5 & 42.0 & 23.4 & 28.7 \\
\hline Date: & $05 / 09 / 2016$ & 23:00 & 25.4 & 24.7 & 22.0 & 5.1 & 19.1 & 46.1 & 26.7 & 15.0 & 21.2 & 33.3 & 21.3 & 39.4 \\
\hline Date: & $06 / 09 / 2016$ & $11: 00$ & 25.8 & 16.5 & 24.8 & 4.7 & 22.6 & 28.0 & 24.4 & 10.5 & 17.6 & 60.5 & 16.6 & 61.5 \\
\hline Date: & $06 / 09 / 2016$ & 23:00 & 27.7 & 17.3 & 24.5 & 20.7 & 26.4 & 8.8 & 27.6 & 13.0 & 17.1 & 80.4 & 17.5 & 65.9 \\
\hline Date: & $07 / 09 / 2016$ & $11: 00$ & 26.3 & 27.3 & 18.3 & 11.6 & 25.1 & 21.2 & 24.9 & 20.0 & 15.4 & 74.0 & 15.8 & 71.1 \\
\hline Date: & $07 / 09 / 2016$ & $23: 00$ & 24.6 & 21.2 & 9.4 & 60.1 & 11.8 & 92.0 & 25.3 & 25.4 & 14.9 & 71.0 & 16.2 & 59.4 \\
\hline Date: & $08 / 09 / 2016$ & $11: 00$ & 19.0 & 41.0 & 7.4 & 68.2 & 9.5 & 99.5 & 22.4 & 30.6 & 14.8 & 70.5 & 14.4 & 96.1 \\
\hline
\end{tabular}

Tabla 48.1: Temperatura y humedad relativa en 850 hPa. Datos de los sondeos de Madrid, La Coruña, Santander, Murcia, Barcelona y Palma de Mallorca.

La Tabla 48.1, muestra los valores de temperatura y humedad relativa a $850 \mathrm{hPa}$ extraídas de los sondeos de Madrid, La Coruña, Santander, Murcia, Barcelona y Palma de Mallorca entre el 5 de septiembre a 00 UTC y el 8 de septiembre a 12 UTC. Solo por citar La Coruña, la temperatura cayó $15.1^{\circ} \mathrm{C}$ en $850 \mathrm{hPa}$ en el periodo de 24 horas entre el 7 de septiembre a las 00 UTC y el 8 de septiembre a las 00 UTC.

\subsection{Resumen final}

La utilización de las herramientas que proporciona el ECENS permite no solo el estudio y evaluación de escenarios alternativos a la predicción, sino la determinación de los grados de probabilidad en casos extremos.

En este caso de estudio se ha utilizado esta técnica para una predicción de temperaturas extremas, pero técnicas similares se utilizan para diferentes casos extremos como precipitación líquida y sólida, viento, estabilidad atmosférica etc.

En definitiva, la atmósfera es un sistema caótico y la predicción de su evolución ha de ser probabilista o no será nada. 


\subsection{Referencias}

[1] PERSSON, Anders. "User guide to ECMWF forecast products". En: Ecmwf March (2011), página 127 (citado en página 743). 